\title{
Development of an analytical procedure for the measurement of nonionic aliphatic polyethoxylated surfactants in raw wastewater ${ }^{1}$
}

\author{
G. Crétier*, C. Podevin and J.-L. Rocca \\ Laboratoire des Sciences Analytiques, Université Claude Bernard - Lyon I, 43, boulevard du 11 novembre 1918, \\ 69622 Villeurbanne Cedex, France
}

\begin{abstract}
An analytical procedure has been developed for determining aliphatic alcohol ethoxylates (AAEs) in raw wastewater. AAEs were isolated by solid-phase extraction on a styrenedivinylbenzene disk. The maximum volume that was processed without plugging of the disk was $20 \mathrm{~mL}$. Then AAEs were desorbed with methanol and, after evaporation to dryness, the residue was analyzed by reversed-phase liquid chromatography coupled to mass spectrometry via atmospheric pressure interface. Two desorption temperatures (ambient and $100{ }^{\circ} \mathrm{C}$ ), two organic modifiers of the mobile phase (methanol and acetonitrile) and two atmospheric pressure interfaces (electrospray and atmospheric pressure chemical ionization) were tested. The lowest coefficients of variation for replicate measurements were obtained by desorbing AAEs from the extraction disk at $100{ }^{\circ} \mathrm{C}$ and by using methanol-based mobile phase with atmospheric pressure chemical ionization source for extract analysis. Under these conditions, all the analytes (ranging in size from 10 to 16 alkyl carbons and from 1 to 25 ethoxylate groups) were recovered at more than $70 \%$ and the limit of quantification (signal-to-noise ratio $=10$ ) ranged between 0.05 and $4 \mu \mathrm{g} \mathrm{L}^{-1}$.
\end{abstract}

Keywords. Alkylethoxylated surfactants - Solid-phase extraction - Liquid chromatography - Mass spectrometry.

\section{Introduction}

Among the three main classes of surfactants (cationic, anionic and nonionic), nonionic surfactants are widely used in many industrial and household cleaning applications, leading to their massive release in wastewater. Most of the data published about the behaviour of nonionic surfactants in these matrices concerned toxicity and biodegradation rate of alkyl phenol ethoxylates and their metabolites, but fewer studies were dedicated to aliphatic alcohol ethoxylates (AAEs) that nevertheless represent the most important class of nonionic surfactants (AAEs correspond to c.a. $55 \%$ of the world production of nonionic surfactants). However, the occurrence of these latter in environment is not quite safe [1] and efficient methods have to be developed to measure their concentrations in environmental matrices.

The structure of AAEs is of major importance in their analysis. Due to their formula, $\mathrm{C}_{n} \mathrm{H}_{2 n+1}\left(\mathrm{OC}_{2} \mathrm{H}_{4}\right)_{x} \mathrm{OH}$, AAEs possess a polar (hydrophilic) and a non-polar (hydrophobic) moiety. The hydrophilic character is provided by the ethoxylate chain usually ranging from 2 to about 20 units. The nonpolar part consists of an alkyl chain containing between 12 and 18 carbon atoms. Consequently, each surface can act as a potential adsorbent for AAEs and the analytical procedure has to provide a good estimate of the true concentration of AAEs in both the liquid (aqueous matrix) and solid (rubbish and sludge) phases of the environmental sample.
Generally, the two phases were isolated by glass microfiber filtration and separately analyzed. Liquid-liquid extraction [2], sublation [3] and mainly solid-phase extraction (SPE) were used to recover AAEs from aqueous matrices. SPE exploited the hydrophobicity of the AAE molecule and employed sorbents were alkyl-bonded silica [4-6] and graphitized carbon black [7, 8]. Extraction of AAEs from the solid phase was carried out using traditional Soxhlet liquidsolid extractor [3]. Extracts are very complex mixtures including several tens to hundreds of individual AAEs which differ in their alkyl chains and in their degrees of ethoxylation. Accurate quantification of each AAE in these complex mixtures requires sophisticated methods. Several recent reviews [9-11] and papers [12,13] discussed the use of chromatography and capillary electrophoresis for the characterization of AAE sample. Liquid chromatography (LC) seemed to be the most suitable separation technique. But, the resolution power of a single liquid chromatographic method being insufficient, the complete analysis of AAEs required either coupling of liquid chromatography with an identification detection mode as mass spectrometry (MS) $[4,5,7,14-$ 17] or combination of two complementary liquid chromatographic methods $[2,18-21]$.

This paper compares different analytical procedures to measure AAEs in wastewater. The methods described are based on reversed-phase liquid chromatography coupled with mass spectrometry detection using atmospheric

1. This work was presented at the chromatographic symposium SEP'99 in Lyon (France), March 31-April 2, 1999.

* Correspondence and reprints.

Received July 20, 1999; revised October 10, 1999; accepted October 15, 1999. 


\section{Original articles}

pressure interface (API). The principal objective was to simplify the extraction technique for determining AAEs simultaneously in liquid and solid phases.

\section{Experimental section}

\section{Chemicals and materials}

The following terminology was used to characterize AAE samples: $\mathrm{C}_{n} \mathrm{AE}_{x}$ designates the individual $\mathrm{AAE}$ with $n$ carbon atoms in its alkyl chain and $x$ ethylene oxide units while $\mathrm{C}_{n} \mathrm{AE}$ globally describes all the oligomers with $\mathrm{n}$ carbon atoms in their alkyl chain. The AAE mixtures denoted by $\mathrm{A}$ and $\mathrm{C}$ were gifts from Lever-France (Hambourdin, France). These mixtures were quantitatively analyzed in terms of both alkyl and ethylene oxide chain lengths by Desbène [22]: $A$ is a mixture of $C_{13}$ and $C_{15}$ homologs; $\mathrm{C}$ consists of even homologs ranging from $\mathrm{C}_{10}$ to $\mathrm{C}_{16}$; both mixtures contains oligomers ranging from 1 to 25 ethylene oxide units and their average degree of ethoxylation is 7 . For method development, a mixture of even and odd homologs was prepared by mixing $\mathrm{A}$ and $\mathrm{C}$ in equal proportions. This new sample denoted by A $+\mathrm{C}$ contains about 120 individual AAEs and, from Desbène's data [22], its percentage weight distribution is accurately known.

Acetone, methanol and acetonitrile, of HPLC grade from SDS (Peypin, France) were used without previous purification. Water was deionized and purified using an Elgastat UHQ II system (Elga, Buckinghamshire, UK). Aqueous $37 \%$ formaldehyde solution was obtained from Fluka (Buchs, Switzerland). Nitrogen of HP45-grade was supplied by Carboxyque Française (Vénissieux, France). The sorbent material, styrenedivinylbenzene of $8 \mu \mathrm{m}$ particle diameter and $8 \mathrm{~nm}$ pore size entrapped into an inert PTFE matrix (Empore 3M extraction disks of $47 \mathrm{~mm}$ diameter and $0.5 \mathrm{~mm}$ thickness), was purchased from Varian (Palo Alto, CA).

\section{Apparatus}

The liquid chromatograph was composed of a LC-10AD high pressure binary gradient system (Shimadzu, Tokyo, Japan), a 7725 i sampling valve equipped with a $2 \mathrm{~mL}$ loop (Rheodyne, Cotati, CA) and a $150 \times 4.6 \mathrm{~mm}$ i.d. column packed with Kromasil C18, $5 \mu \mathrm{m}$ (Eka Chemicals, Bohus, Sweden) as stationary phase. The outlet from the column was connected to a LCQ ion trap mass spectrometer (Thermo Separation Products, San Jose, CA) via an electrospray ionization (ESI) or an atmospheric pressure chemical ionization (APCI) source.

At room temperature, solid-phase extractions were performed with a $47 \mathrm{~mm}$ glass filtering apparatus using a vacuum source (Waters, Milford, MA). For extractions carried out at $100{ }^{\circ} \mathrm{C}$, a home-built extractor was used (Fig. 1). The Shimadzu Model LC-5A pump supplied solvent through the $1 \mathrm{~m} \times 0.25 \mathrm{~mm}$ i.d. stainless steel preheating coil to the extraction cell placed inside the Carlo Erba (Milan, Italy)

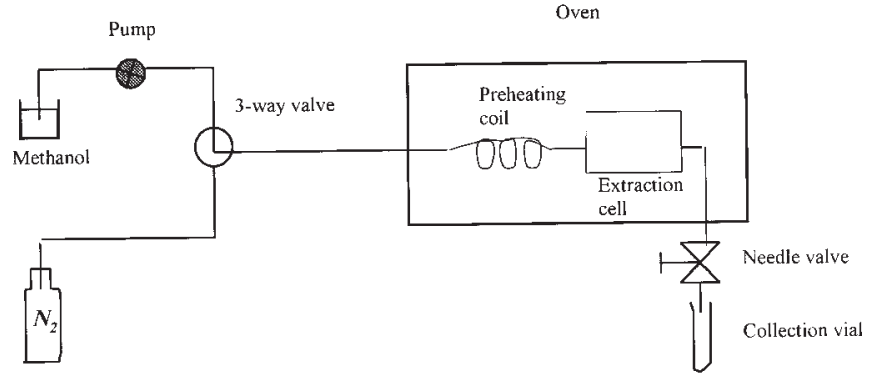

Fig. 1. Diagram of the experimental system used for extractions at $100{ }^{\circ} \mathrm{C}$.

SFC 3000 oven. The $3 \mathrm{~mL}$ extraction cell which was a $250 \times 4 \mathrm{~mm}$ i.d. tubing equipped with $2 \mu \mathrm{m}$ stainless steel frits at both ends, was connected to the stainless steel needle valve (Swagelok, Solon, $\mathrm{OH}$ ) used as flow control device. After each extraction, the system was purged with nitrogen gas via the three-way valve (Swagelok).

\section{Sample collection and conservation}

The wastewater sample studied was collected during January from influents of the Nievroz sewage treatment plant in the area of Lyon (France). A wastewater volume of $2 \mathrm{~L}$ was taken within $24 \mathrm{~h}$ by an automatic flow proportional sampler. Immediately after collection, the sample was preserved by addition of $150 \mathrm{~mL}$ of a $37 \%$ formaldehyde solution, as recommended by Fedinger [6], and aliquots of $20 \mathrm{~mL}$ were prepared under vigorous shaking to ensure adequate mixing and suspension of particulated material. $20 \mathrm{~mL}$ corresponds to the maximum wastewater volume that can be processed without plugging of the extraction disk. These aliquots were stored in darkness at $4{ }^{\circ} \mathrm{C}$.

\section{Sample spiking and extraction}

Extraction procedure was applied to unspiked wastewater samples, UHQ water spiked for less than $1 \mathrm{~h}$ (freshly spiked UHQ water samples) and wastewater samples spiked for 75 days (aged spiked wastewater samples). The spiking operation consisted of adding $1 \mathrm{~mL}$ of the mixture $\mathrm{A}+\mathrm{C}$ at the total concentration of $10 \mathrm{mg} \mathrm{L}^{-1}$ to each sample aliquot of $20 \mathrm{~mL}$.

Before sample processing, the sorbent disk was conditioned and the extraction operation involved passing through the disk sequentially $10 \mathrm{~mL}$ of acetone, twice $10 \mathrm{~mL}$ of methanol, $25 \mathrm{~mL}$ of UHQ water and, finally, the sample to extract. At each step, the liquid phase was allowed to soak the disk by venting vacuum for $3 \mathrm{~min}$ and, between two steps, the disk was prevented from drying by adding the next liquid phase as soon as the liquid surface was $3-5 \mathrm{~mm}$ above the disk surface.

After sample extraction, AAEs were desorbed from the disk by using methanol either at room temperature or at 
$100{ }^{\circ} \mathrm{C}$. For AAE elution at room temperature, $10 \mathrm{~mL}$ of methanol were immediately poured on the disk and, after $3 \mathrm{~min}$ of soaking, vacuum was applied and $20 \mathrm{~mL}$ of methanol were added with a pipet, washing the walls of the reservoir. Use of a larger volume of methanol do not improve AAE desorption. Residual methanol was removed by applying vacuum for $10 \mathrm{~min}$ to dry the disk. For AAE recovery at $100{ }^{\circ} \mathrm{C}$, the extraction disk was first put to dry in a dessicator for 3 days. Then, it was cut into very small pieces and loaded into the extraction cell. Extraction was performed by the prefill method. Methanol was continuously delivered by the pump operating at the constant pressure of 150 bar. In the first step, the needle valve was partially closed so that the solvent flow-rate was $1 \mathrm{~mL} \mathrm{~min}^{-1}$. After about $1 \mathrm{~mL}$ had accumulated into the collection vial, the needle valve was tightened and the sample cell was heated to $100{ }^{\circ} \mathrm{C}$. During the heat-up period of $5 \mathrm{~min}$, the solvent expanded and escaped from the cell at the rate of approximately $50 \mu \mathrm{L} \mathrm{min}^{-1}$. After the oven reached the set point temperature, the cell was allowed to equilibrate for $10 \mathrm{~min}$. After this pseudo-static extraction, the needle valve was reopened and $5 \mathrm{~mL}$ of fresh solvent was pumped at approximately $1 \mathrm{~mL} \mathrm{~min}^{-1}$ to rinse the lines and cell. As a final step, the rinsing solvent was recovered by flushing the circuit with gaseous nitrogen. The total volume of solvent used for each extraction at $100{ }^{\circ} \mathrm{C}$ was $12 \mathrm{~mL}$.

Extraction recovery of each AAE was calculated by comparing the difference between the AAE amounts recovered from spiked and unspiked samples of the same type (UHQ water or wastewater) to the spike level.

\section{Chromatographic conditions and extract analysis}

Chromatographic separations were performed at a flow-rate of $800 \mu \mathrm{L} \mathrm{min}{ }^{-1}$, either with a water-methanol gradient or with a water-acetonitrile gradient. In the first case, the mobile phase composition was initially water-methanol 20/80 (v/v) and then linearly progammed to water-methanol $0 / 100(\mathrm{v} / \mathrm{v})$ in $40 \mathrm{~min}$. In the second case, the acetonitrile proportion was linearly increased from $50 \%$ to $100 \%$ with a slope of $0.5 \% \mathrm{~min}^{-1}$.

Whatever the ionization source used (ESI or APCI), the mass spectrometer was operated in the positive-ion mode, mass spectrometric data were acquired in full scan mode over the range $150<\mathrm{m} / \mathrm{z}<2000$, the maximum injection time in the ion trap was $400 \mathrm{~ms}$ and nitrogen was used as drying, sheath and nebulizing gas. In ESI experiments, the voltage applied to the introduction needle was $5.6 \mathrm{kV}$ and the transfer capillary was heated at $220^{\circ} \mathrm{C}$. The APCI source conditions were as follows: corona discharge current, $10 \mu \mathrm{A}$; vaporization temperature, $480{ }^{\circ} \mathrm{C}$; transfer capillary temperature, $170{ }^{\circ} \mathrm{C}$. For a given AAE and given ionization conditions, the obtained ions are always the same ones but between-day fluctuations in the distribution of the different ions were observed; therefore, in order to achieve a sufficiently accurate measurement of the analyte, the chromatogram of a specific AAE was reconstructed from the total ion current (TIC) chromatogram by summing the ion currents corresponding to the three most significant adducts (it would be better if all the ion signals were summed but the mass spectrometer software does not allow to sum more than three signals simultaneously).

For extract analysis, the extraction solvent was first evaporated to dryness under a gentle flow of nitrogen. Then, the residual material was dissolved in $1 \mathrm{~mL}$ of water-methanol $50 / 50(\mathrm{v} / \mathrm{v})$ and the total volume was injected in the separation column. Amounts of the individual AAEs in the different extracts were calculated from measurement of the peak area in the reconstructed chromatogram and external calibration with the mixture $\mathrm{A}+\mathrm{C}$.

\section{Results and discussion}

\section{Analysis of AAEs by LC-API-MS}

The mild conditions used for ionization yield mass spectra with little fragmentation. Figure 2 shows typical spectra obtained with ESI and APCI sources. Peaks of $(\mathrm{M}+\mathrm{H})^{+}$and $\left(\mathrm{M}+\mathrm{NH}_{4}\right)^{+}$ions were identified as the most significant peaks in APCI spectra (Fig. 2a). ESI spectra (Fig. 2b) reveal the presence of two additional adducts, $(\mathrm{M}+\mathrm{Na})^{+}$and to a lower degree $(\mathrm{M}+\mathrm{K})^{+}$; but the $(\mathrm{M}+\mathrm{K})^{+}$signal cannot be taken into account for the reconstruction of the individual ESI chromatograms. Although $(\mathrm{M}+\mathrm{H})^{+},(\mathrm{M}+\mathrm{Na})^{+}$and $(\mathrm{M}+\mathrm{K})^{+}$ions are very common with the API sources, the origin of the $\left(\mathrm{M}+\mathrm{NH}_{4}\right)^{+}$ions is not clear; they probably result from some pollution of either ionization sources or glassware. The spectra observed with a given ionization mode (ESI or APCI) are identical whether the solute is eluted in an acetonitrile- or methanol-based mobile phase.

The chromatograms obtained for the mixture $\mathrm{A}+\mathrm{C}$ with the two gradient conditions are reported in figures 3 and 4 . The TIC chromatograms show that selectivity depends on organic modifier. With water-methanol gradient (Fig. 3a), the homologs are separated according to the length of their alkyl chain with co-elution of the oligomers belonging to a given homolog. By changing methanol to acetonitrile (Fig. 4a), the homolog peaks split off into oligomer peaks whose retention increases with decreasing number of ethylene oxide units; but, the oligomer distributions overlap when the two homologs differ from only one carbon atom. The reconstructed chromatograms for individual AAEs contain either one peak (Fig. 3b and 4b) or several peaks (Fig. 3c and 4c). In this latter case, the minor peaks eluted prior to the major one were demonstrated to result from branched isomers of the considered AAE [23]. Of course, the separation obtained under given elution conditions (with methanol or acetonitrile) does not depend on the ionization source used.

So, from the two gradient conditions and the two ionization sources, four methods can be used to analyze AAEs: water-methanol gradient with ESI source (denoted by $\mathrm{MeOH}+\mathrm{ESI}$ ), water-methanol gradient with APCI source $(\mathrm{MeOH}+\mathrm{APCI})$, water-acetonitrile gradient with ESI source $(\mathrm{ACN}+\mathrm{ESI})$ and water-acetonitrile with APCI source 

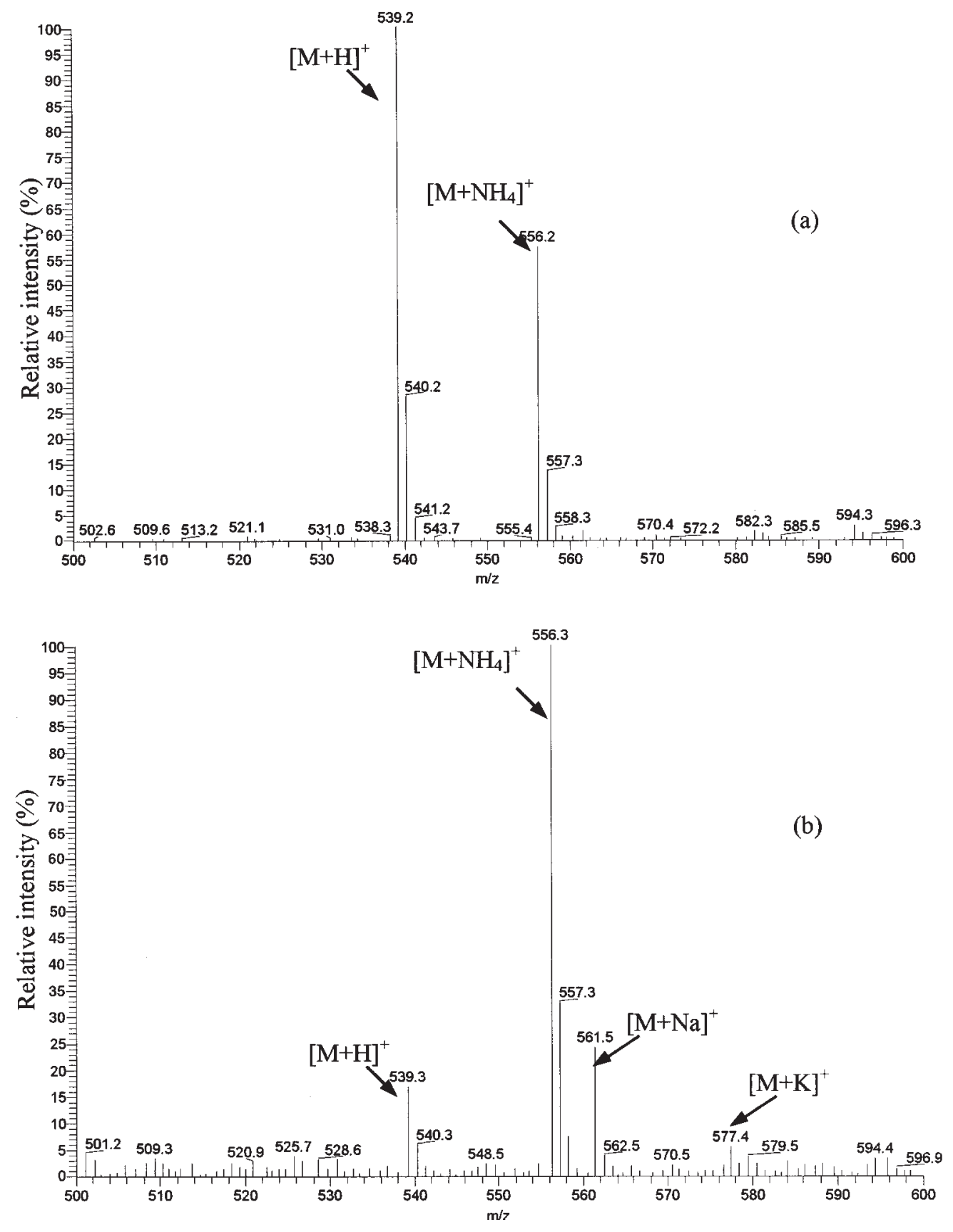

Fig. 2. LC-MS spectra obtained with APCI (a) and ESI (b) for $\mathrm{C}_{12} \mathrm{AE}_{8}$ contained in the mixture $\mathrm{A}+\mathrm{C}$ and eluted with water-acetonitrile gradient.

$(\mathrm{ACN}+\mathrm{APCI})$. We compared the precision of these four different methods and table I gives peak area reproducibility obtained for three repetitive analyses of the mixture $\mathrm{A}+\mathrm{C}$ carried out over a 1-day period. Precision is quite good only for the method using the water-methanol gradient in combination with the APCI source: the coefficients of variation seldom exceed $3 \%$ with the $\mathrm{MeOH}+$ APCI method while they can reach several tens of percent with the three other ones.

Consequently, the MeOH + APCI method was selected to quantitatively analyze AAEs from extracts of wastewater. 


\section{Original articles}
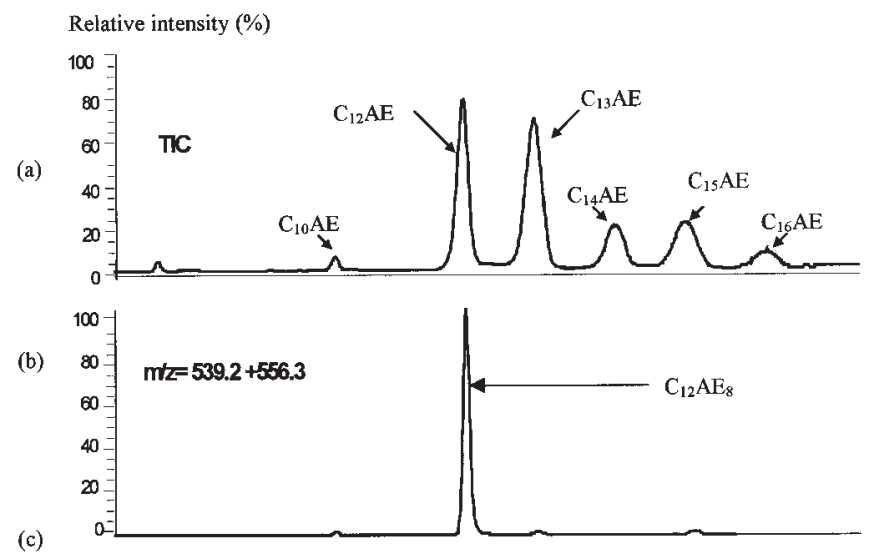

(c)

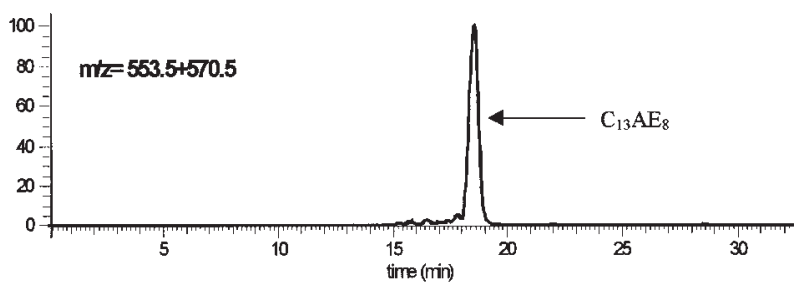

Fig. 3. LC-APCI-MS chromatograms obtained for the mixture $\mathrm{A}+\mathrm{C}$. Elution conditions, water-methanol gradient. Injected concentration, $2 \mathrm{~g} \mathrm{~L}^{-1}$. Injected volume, $5 \mu \mathrm{L}$. (a) TIC chromatogram; (b) reconstructed chromatogram of $\mathrm{C}_{12} \mathrm{AE}_{8}$. (c) reconstructed chromatogram of $\mathrm{C}_{13} \mathrm{AE}_{8}$.

Table I. Coefficients of variation (\%) of peak area measurement observed for three repetitive analyses of the mixture $\mathrm{A}+\mathrm{C}$ with the four possible methods. Injected concentration, $2 \mathrm{~g} \mathrm{~L}^{-1}$. Injected volume, $5 \mu \mathrm{L}$.

\begin{tabular}{lcccc}
\hline \multicolumn{5}{c}{$\mathrm{MeOH}+\mathrm{ESI}$} \\
\hline $\mathrm{C}_{12} \mathrm{AE}_{17}$ & 10 & 2 & 15 & 10 \\
$\mathrm{C}_{12} \mathrm{AE}_{8}$ & 13 & 2 & 13 & 12 \\
$\mathrm{C}_{12} \mathrm{AE}_{3}$ & 21 & 1 & 17 & 6 \\
$\mathrm{C}_{13} \mathrm{AE}_{17}$ & 10 & 3 & 6 & 11 \\
$\mathrm{C}_{13} \mathrm{AE}_{8}$ & 14 & 1 & 14 & 15 \\
$\mathrm{C}_{13} \mathrm{AE}_{3}$ & 13 & 8 & 20 & 16 \\
$\mathrm{C}_{14} \mathrm{AE}_{16}$ & 7 & 3 & 7 & 29 \\
$\mathrm{C}_{14} \mathrm{AE}_{8}$ & 11 & 3 & 32 & 12 \\
$\mathrm{C}_{14} \mathrm{AE}_{3}$ & 7 & 2 & 20 & 10 \\
$\mathrm{C}_{15} \mathrm{AE}_{17}$ & 7 & 2 & 10 & 14 \\
$\mathrm{C}_{15} \mathrm{AE}_{8}$ & 9 & 1 & 17 & 13 \\
$\mathrm{C}_{15} \mathrm{AE}_{3}$ & 11 & 7 & 30 & 11 \\
\hline
\end{tabular}

But, first, its performances were studied. Response factors for individual AAEs were assessed from the preceding experiments, by dividing each peak area by the corresponding injected amount of AAE calculated from the injection conditions (injected total concentration, $2 \mathrm{~g} \mathrm{~L}^{-1}$; injected volume, $5 \mu \mathrm{L}$ ) and the percentage weight distribution of AAE in the mixture $\mathrm{A}+\mathrm{C}$. As can be seen in figure 5, the detector response for AAE species in the $\mathrm{MeOH}+\mathrm{APCI}$ method

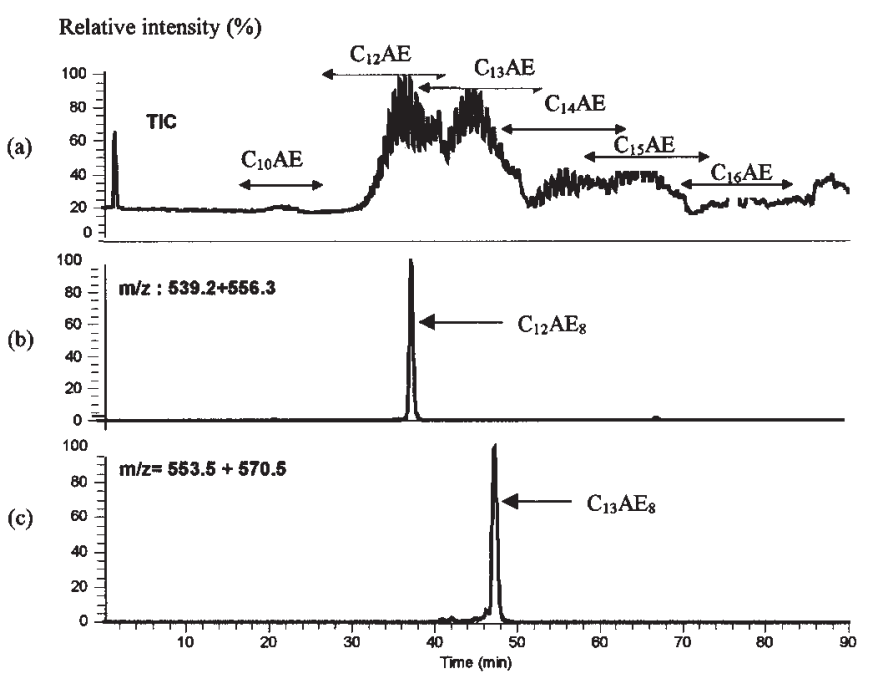

Fig. 4. LC-APCI-MS chromatograms obtained for the mixture $\mathrm{A}+\mathrm{C}$. Elution conditions, water-acetonitrile gradient. Injected concentration, $2 \mathrm{~g} \mathrm{~L}^{-1}$. Injected volume, $5 \mu \mathrm{L}$. (a) TIC chromatogram; (b) reconstructed chromatogram of $\mathrm{C}_{12} \mathrm{AE}_{8}$. (c) reconstructed chromatogram of $\mathrm{C}_{13} \mathrm{AE}_{8}$.

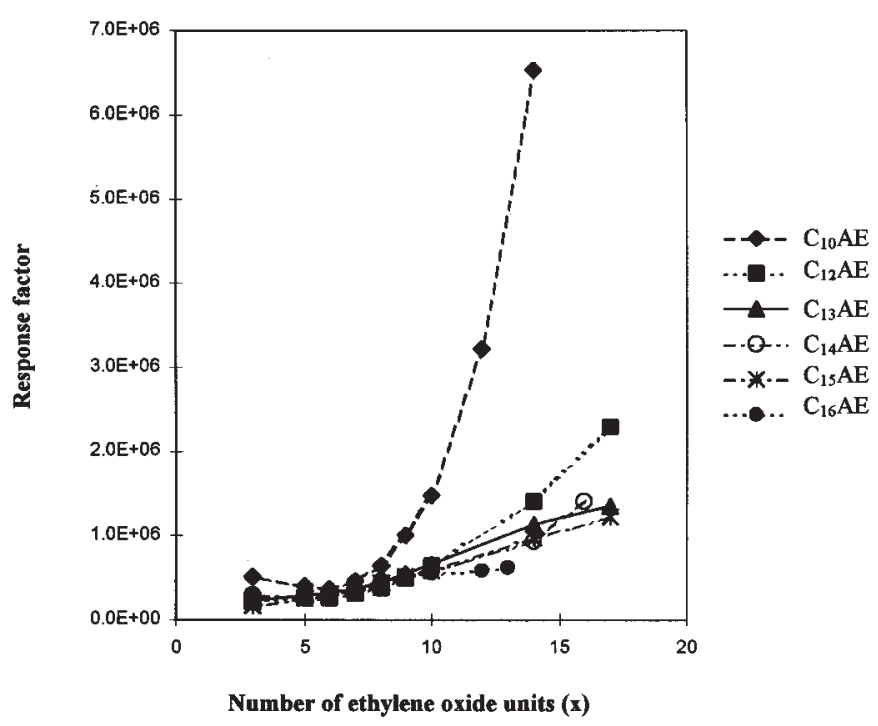

Fig. 5. Dependence of AAE response (arbitrary units) on both the number of ethylene oxide units and the alkyl chain length. Elution conditions, water-methanol gradient. Ionization source, APCI.

increases with the number of ethylene oxide units, especially for degrees of ethoxylation higher than 7 , and this increase is much more pronounced for shorter homologs. The limit of quantification of each AAE, denoted by LOQ and defined as the AAE amount corresponding to a signal-to-noise ratio of 10 , was experimentally determined by injecting decreasing amounts of the mixture $\mathrm{A}+\mathrm{C}$. LOQ varies from $1 \mathrm{ng}$ for $\mathrm{C}_{10} \mathrm{AE}_{14}$ to $80 \mathrm{ng}$ for $\mathrm{C}_{16} \mathrm{AE}_{3}$. For samples of $20 \mathrm{~mL}$ 


\section{Original articles}

(volume that can be processed by extraction), this corresponds to relative LOQ of $0.05 \mu \mathrm{g} \mathrm{L}^{-1}$ for $\mathrm{C}_{10} \mathrm{AE}_{14}$ and $4 \mu \mathrm{g} \mathrm{L}^{-1}$ for $\mathrm{C}_{16} \mathrm{AE}_{3}$. The linear dynamic range was also investigated. For $\mathrm{C}_{10} \mathrm{AE}_{14}$, the calibration curve indicates a fairly good linear response (the correlation coefficient of this curve is 0.993 ) up to $5400 \mathrm{ng}$ injected into the column. The linearity range is less expanded for AAEs with a lower degree of ethoxylation: for $\mathrm{C}_{16} \mathrm{AE}_{3}$, the response curve becomes non-linear when the injected amount exceeds $450 \mathrm{ng}$.

\section{Determination of AAEs in wastewater samples}

The applicability of the $\mathrm{MeOH}+\mathrm{APCI}$ method to environmental samples is demonstrated by comparing the chromatograms obtained for an extract of unspiked wastewater sample (Fig. 6) to those obtained for the mixture A + C (Fig. 7). The wastewater extract was analyzed without further cleanup and its TIC chromatogram (Fig. 6a) includes large non-resolved peaks resulting from many non-AAE species. Parts b-e of figures 6 and 7 show the reconstructed chromatograms of some oligomers of $\mathrm{C}_{13} \mathrm{AE}$. These chromatograms illustrate the excellent resolution obtained with the $\mathrm{MeOH}+\mathrm{APCI}$ method - even for a sample as dirty as treatment plant influent. The few interferences observed in the reconstructed chromatograms for the wastewater extract (Fig. 6b-e) are always separated from the AAE peak. Moreover, there is no matrix effect and retention times of AAEs are identical for the wastewater sample (Fig. 6b-e) and the standard mixture (Fig. 7b-e).

The $\mathrm{MeOH}+\mathrm{APCI}$ method was used to assess the precision of AAE extraction by methanol according to both the sample type and the extraction temperature. Results are reported in table II. At room temperature, the analytical procedure showed very acceptable precision only for the UHQ water samples freshly spiked with the mixture $\mathrm{A}+\mathrm{C}$ : in this case, the coefficients of variation of AAE extraction recoveries obtained for the overall method, including extraction and analysis by the $\mathrm{MeOH}+$ APCI method, ranged from 2 to $9 \%$ and they were of the same order of magnitude than those obtained for the direct analysis of the mixture A + C (Tab. I), i.e. without extraction step. On the contrary, the coefficients of variation obtained for aged spiked wastewater samples at room temperature, ranging from 18 to $40 \%$, were anomalously large and these figures should be the result of adsorption of AAEs on suspended solids present in wastewater samples. Due to their hydrophobic nature, AAEs were shown to be mainly associated with the solid phase in influent samples [3] and the most probable explanation of the non-reproducibility of recoveries is that sorption of AAEs causes an inefficient extraction when working at room temperature. The increase of precision observed when aged spiked wastewater samples were extracted at $100{ }^{\circ} \mathrm{C}$, confirms this hypothesis: under these conditions, the coefficients of variation of AAE extraction recoveries varied between 4 and $15 \%$ and were notably improved compared to those obtained at room temperature. Then, it became possible to assess the accuracy of the analytical procedure from the
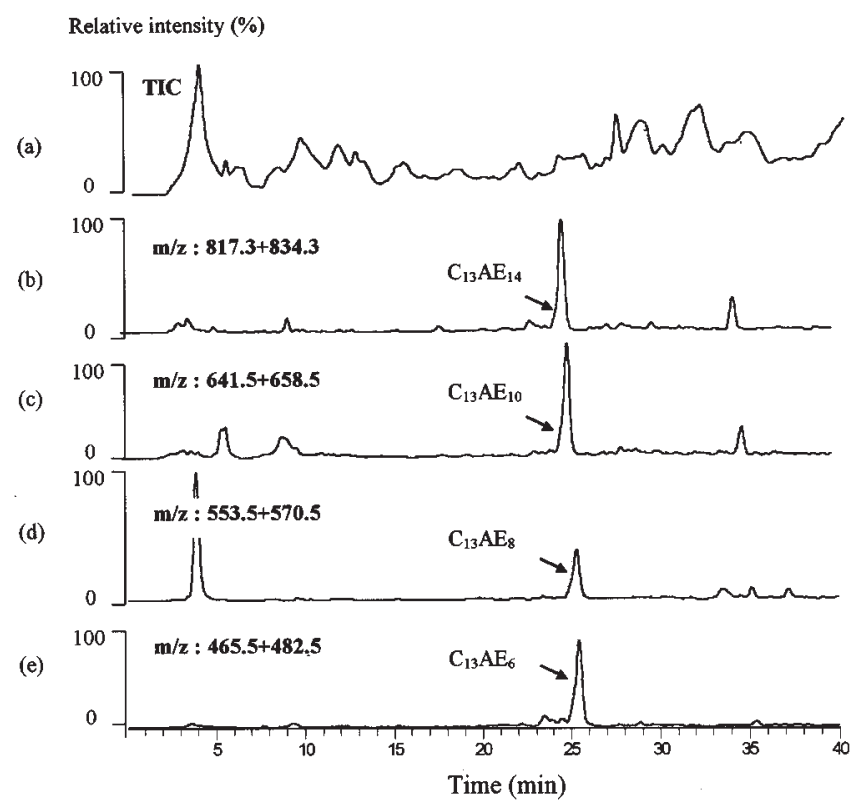

Fig. 6. LC-APCI-MS chromatograms obtained for a sample of unspiked wastewater extracted at room temperature. Elution conditions, water-methanol gradient. (a) TIC chromatogram; (b) reconstructed chromatogram of $\mathrm{C}_{13} \mathrm{AE}_{14}$; (c) reconstructed chromatogram of $\mathrm{C}_{13} \mathrm{AE}_{10}$; (d) reconstructed chromatogram of $\mathrm{C}_{13} \mathrm{AE}_{8}$; (e) reconstructed chromatogram of $\mathrm{C}_{13} \mathrm{AE}_{6}$.

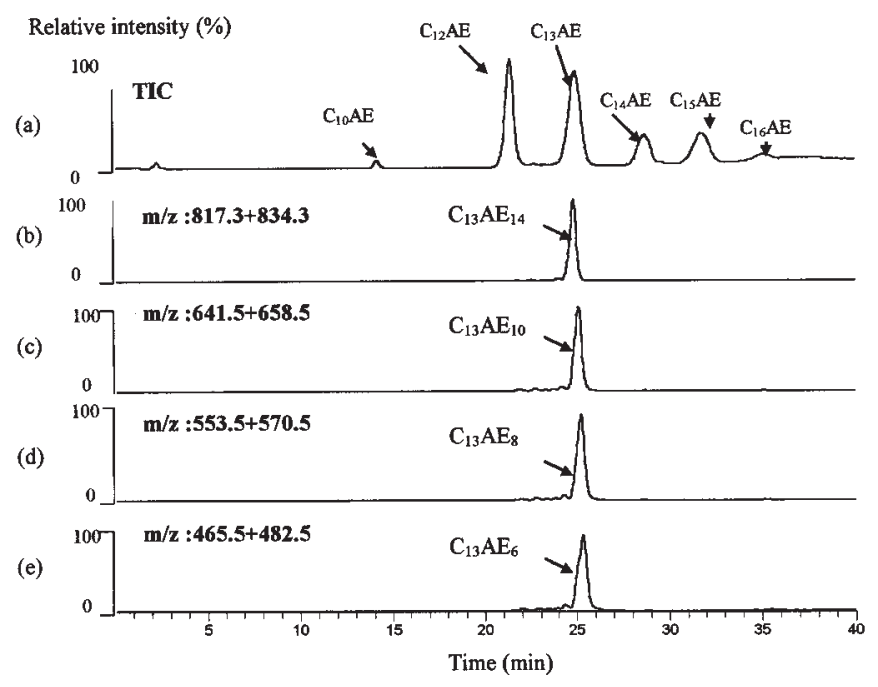

Fig. 7. LC-APCI-MS chromatograms obtained for the mixture $\mathrm{A}+\mathrm{C}$. Elution conditions, water-methanol gradient. Injected concentration, $10 \mathrm{mg} \mathrm{L}^{-1}$. Injected volume, $1 \mathrm{~mL}$. (a) TIC chromatogram; (b) reconstructed chromatogram of $\mathrm{C}_{13} \mathrm{AE}_{14}$; (c) reconstructed chromatogram of $\mathrm{C}_{13} \mathrm{AE}_{10} ;$ (d) reconstructed chromatogram of $\mathrm{C}_{13} \mathrm{AE}_{8}$; (e) reconstructed chromatogram of $\mathrm{C}_{13} \mathrm{AE}_{6}$.

average AAE recoveries calculated for the extraction of three spiked aliquots of aged wastewater (Tab. III). 


\section{Original articles}

Table II. Coefficients of variation (\%) of AAE extraction recoveries observed for different sample types and different extraction temperatures (three aliquots of each sample were extracted in each case).

\begin{tabular}{lccc}
\hline \multicolumn{3}{c}{$\begin{array}{c}\text { Freshly spiked UHQ water } \\
\text { Room }\end{array}$ temperature } & \multicolumn{2}{c}{ Aged spiked wastewater } \\
& Roomperature & 100 \\
& ${ }^{\circ} \mathrm{C}$ \\
\hline $\mathrm{C}_{12} \mathrm{AE}_{14}$ & 3 & 36 & 12 \\
$\mathrm{C}_{12} \mathrm{AE}_{8}$ & 4 & 22 & 8 \\
$\mathrm{C}_{12} \mathrm{AE}_{6}$ & 5 & 26 & 4 \\
$\mathrm{C}_{13} \mathrm{AE}_{14}$ & 4 & 23 & 6 \\
$\mathrm{C}_{13} \mathrm{AE}_{8}$ & 5 & 18 & 7 \\
$\mathrm{C}_{13} \mathrm{AE}_{6}$ & 3 & 28 & 13 \\
$\mathrm{C}_{14} \mathrm{AE}_{14}$ & 9 & 31 & \\
$\mathrm{C}_{14} \mathrm{AE}_{8}$ & 4 & 31 & 12 \\
$\mathrm{C}_{14} \mathrm{AE}_{6}$ & 4 & 35 & 7 \\
$\mathrm{C}_{15} \mathrm{AE}_{14}$ & 2 & 30 & 10 \\
$\mathrm{C}_{15} \mathrm{AE}_{8}$ & 2 & 34 & 15 \\
$\mathrm{C}_{15} \mathrm{AE}_{6}$ & 3 & 40 & 12 \\
\hline
\end{tabular}

Table III. Average AAE extraction recoveries (\%) obtained for three spiked aliquots of aged wastewater extracted at $100{ }^{\circ} \mathrm{C}$.

\begin{tabular}{lc}
\hline $\mathrm{C}_{12} \mathrm{AE}_{14}$ & 73 \\
$\mathrm{C}_{12} \mathrm{AE}_{8}$ & 80 \\
$\mathrm{C}_{12} \mathrm{AE}_{6}$ & 93 \\
$\mathrm{C}_{13} \mathrm{AE}_{14}$ & 78 \\
$\mathrm{C}_{13} \mathrm{AE}_{8}$ & 83 \\
$\mathrm{C}_{13} \mathrm{AE}_{6}$ & 98 \\
$\mathrm{C}_{14} \mathrm{AE}_{14}$ & 102 \\
$\mathrm{C}_{14} \mathrm{AE}_{8}$ & 96 \\
$\mathrm{C}_{14} \mathrm{AE}_{6}$ & 105 \\
$\mathrm{C}_{15} \mathrm{AE}_{14}$ & 108 \\
$\mathrm{C}_{15} \mathrm{AE}_{8}$ & 90 \\
$\mathrm{C}_{15} \mathrm{AE}_{6}$ & 96 \\
\hline
\end{tabular}

AAE recoveries ranged from 73 to $108 \%$ and some losses of the added AAEs are mainly observed for the shorter homologs. Some biodegradation of these latter components could explain the results: the central cleavage of the molecule, leading to the formation of polyethylene glycol and aliphatic alcohol, is the most important pathway for the aerobic biodegradation of AAEs and this mechanism is all the more easy since the alkyl chain is short [24].

\section{Conclusions}

The proposed analytical procedure for the quantification of individual AAEs in environmental samples is based on three steps: ( $i$ ) filtration of the sample on a styrenedivinylbenzene disk; (ii) desorption of the solutes with methanol at $100{ }^{\circ} \mathrm{C}$; (iii) analysis of the extract by LC-APCI-MS under watermethanol gradient conditions. Neither separation of samples into their liquid and solid phases nor prior clean-up is required. This method was validated by AAE recoveries from wastewater samples spiked with a standard mixture containing about 120 individual AAEs. It copes typically with 0.01 to $1 \mu \mathrm{g} \mathrm{L}^{-1}$ concentration levels and it can distinguish the various homologs and oligomers as well as the highly branched AAEs from the linear ones of identical molecular weight and formula.

\section{References}

1. Lewis, M. A. Wat. Res. 1991, 25, 101.

2. Schmitt, T. M.; Allen, M. C.; Brain, D. K.; Guin, K. F.; Lemmel, D. E.; Osburn, Q. W. J. Am. Oil Chem. Soc. 1990, 67, 103.

3. Kiewiet, A. T.; Van der Steen, J. M. D.; Parsons, J. R. Anal. Chem. 1995, 67, 4409.

4. Schröder, H. Fr. J. Chromatogr. 1993, 647, 219.

5. Evans, K. A.; Dubey, S. T.; Kravetz, L.; Dzidic, I.; Gumulka, J. Anal. Chem. 1994, 66, 699.

6. Fedinger, N. J.; Begley, W. M.; Mac Avoy, D. C.; Seckhoff, W. Environ. Sci. Technol. 1995, 29, 856.

7. Crescenzi, C.; Di Corcia, A.; Samperi, R.; Marcomini, A. Anal. Chem. 1995, 67, 1797.

8. Marcomini, A.; Pojana, G.; Patrolecco, L.; Capri, S. Analusis 1998, 26, 64

9. Kiewiet, A. T.; De Voogt, P. J. Chromatogr. A 1996, 733, 185.

10. Marcomini, A.; Zanette, M. J. Chromatogr. A 1996, 733, 193.

11. Cserhati, T.; Forgacs, E. J. Chromatogr. A 1997, 774, 265.

12. Di Corcia, A. J. Chromatogr. A 1998, 794, 165.

13. Heinig, K.; Vogt, C.; Werner, G. Anal. Chem. 1998, 70, 1885.

14. Schröder, H. Fr. J. Chromatogr. A 1995, 712, 123.

15. Schröder, H. Fr. In Applications of LC-MS in environmental chemistry; Barcelo, D., Ed.; J. Chromatogr. Library, Vol. 59; Elsevier : Amsterdam, The Netherlands, 1996; p 263.

16. Popenoe, D. D.; Morris, P. S.; Horn, P.S., Norwood, K. T. Anal. Chem. 1994, 66, 1620.

17. Jandera, P.; Holcapek, M.; Theodoridis, G. J. Chromatogr. A 1998, 813, 299.

18. Okada, T. J. Chromatogr. A 1992, 609, 213.

19. Nitschke, L.; Huber, L. Fresenius J. Anal. Chem. 1993, 345, 585.

20. Murphy, R. E.; Schure, M. R.; Foley, J. P. Anal. Chem. 1998, $70,4353$.

21. Crétier, G.; Podevin, C.; Rocca, J. L., submitted for publication in J. Chromatogr. A.

22. Desbène, P-L. ; Portet, F.I. ; Goussot, G.J. J. Chromatogr. A 1996, 730, 209.

23. Podevin, C. Ph. D. Thesis, University Claude Bernard at Lyon, France, Oct. 1998.

24. Kravetz, L.; Salanitro, J.P.; Dorn, P.B.; Guin, K.F. J. Am. Oil Chem. Soc. 1991, 68, 610. 